\title{
Response to Letter to the Editor: Postoperative Low Back Pain after Posterior Lumbar Interbody Fusion Surgery Using Cortical Bone Trajectory Screws
}

\author{
Nozumu Nakajima, Takahiro Maenaka, Hiroki Kano \\ Department of Orthopaedic Surgery, Osaka General Medical Center, Osaka, Japan
}

Dear Sir,

We are truly grateful for the opportunity to respond to this Letter to the Editor concerning our recently published study entitled "Postoperative low back pain after posterior lumbar interbody fusion surgery using cortical bone trajectory screws [1].”

In response to the comments:

Facet joint violation would be a cause of postoperative low back pain [2]. We directly visualized an entry point in the open procedure and carefully inserted cortical bone trajectory (CBT) screws with the assistance of both lateral and anteroposterior fluoroscopy. Postoperative computed tomography revealed that facet joint violations were observed in $22 \%$ of our CBT-treated patients. They were all grade 1 violations (screw shaft or screw head in contact with the facet joint) [3] and were not associated with postoperative low back pain. In order to avoid facet joint violations, an entry point should be created far away from the facet joint as mentioned elsewhere. We preferred the largest possible screw in both length and diameter in order to increase the fixation strength [4]. The diameter of the screws was $5.5 \mathrm{~mm}$ in most cases. We agree that it is difficult to design an entry point of CBT screws in patients with severely degenerated and destructed articular joints. In those cases, conventional pedicle screws should be considered rather than CBT screws.

\section{Conflict of Interest}

No potential conflict of interest relevant to this article was reported.

\section{References}

1. Nakajima N, Maenaka T, Kano H. Postoperative low back pain after posterior lumbar interbody fusion surgery using cortical bone trajectory screws. Asian Spine J 2020;14:655-62.

2. Matsukawa K, Kato T, Yato Y, et al. Incidence and risk factors of adjacent cranial facet joint violation following pedicle screw insertion using cortical bone trajectory technique. Spine (Phila Pa 1976) 2016;41:E8516.

3. Seo HY, Chung JY, Kang KD, et al. Transpedicular

Received Dec 1, 2020; Accepted Dec 8, 2020

Corresponding author: Hiroki Kano

Department of Orthopaedic Surgery, Osaka General Medical Center, 3-1-56 Bandaihigashi, Sumiyoshi, Osaka, 558-8558, Japan

Tel: +81-6-6692-1201, Fax: +81-6-6606-7000, E-mail: kano45411@gmail.com 
screw violation of facet joint could lead to adjacent segment degeneration. Proceedings of the the American Academy of Orthopaedic Surgeons; 2011 Feb 16; San Diego, USA. Rosemont (IL): American Academy of Orthopaedic Surgeons; 2011.
4. Matsukawa K, Yato Y, Imabayashi H, et al. Biomechanical evaluation of fixation strength among different sizes of pedicle screws using the cortical bone trajectory: what is the ideal screw size for optimal fixation? Acta Neurochir (Wien) 2016;158:465-71. 